\title{
Pattern analysis of a linear dune field on the northern margin of Qarhan Salt Lake, northwestern China
}

\author{
LI Jiyan ${ }^{*}$, DONG Zhibao ${ }^{2}$, QIAN Guangqiang ${ }^{2}$, ZHANG Zhengcai ${ }^{2}$, LUO Wanyin ${ }^{2}$, LU \\ Junfeng ${ }^{2}$, WANG Meng ${ }^{2}$ \\ ${ }^{1}$ Taiyuan Normal University, Jinzhong 030619, China; \\ ${ }^{2}$ Key Laboratory of Desert and Desertification, Cold and Arid Regions Environmental and Engineering Research Institute, \\ Chinese Academy of Sciences, Lanzhou 730000, China
}

\begin{abstract}
In terms of formation mechanisms of linear dunes, there are open arguments for their widespread distribution and multi-morphological diversities. In order to clarify the formation mechanism of linear dunes of Qarhan Salt Lake, we used pattern analysis method to analyze the statistical characteristics and spatial variation of their pattern parameters. Except at the west-northwest margin, the pattern parameters showed regular spatial variation from the up-middle part towards the downwind end of the dune field. Based on the cumulative probability plots for inter-crest spacing and crest length, we divided the linear dunes into three groups, which corresponding to the three evolution stages of these dunes. The first group comprises erosional relics, with shorter crests, smaller inter-crest spacing and more random dune orientation. The second group comprises dunes whose sand supply is just sufficient to maintain stability and these dunes are approaching the net erosion stage. The crest length and inter-crest spacing of these dunes are much larger than those of the first group, and dune orientation is closer to the resultant drift direction (RDD). The last group comprises linear dunes that are still undergoing vertical accretion and longitudinal elongation, which follows the RDD of the modern wind regime. The presence of regular spatial variation of pattern parameters and a similar geometry with the vegetated linear dunes suggest that deposition and erosion coexist in the development and evolution of linear dunes of Qarhan Salt Lake, i.e. deposition predominates at the downwind end of linear dunes in the vertical accretion and longitudinal elongation stage, whereas erosion mainly occurs at the upwind end of linear dunes in the degradation stage. Therefore, the formation mechanism of linear dunes in Qarhan Salt Lake can be reasonably explained by the combination of depositional and erosional theories.
\end{abstract}

Keywords: pattern analysis; self-organization; linear dunes; dune field; Qarhan Salt Lake; Qaidam Basin

Citation: LI Jiyan, DONG Zhibao, QIAN Guangqiang, ZHANG Zhengcai, LUO Wanyin, LU Junfeng, WANG Meng. 2016. Pattern analysis of a linear dune field on the northern margin of Qarhan Salt Lake, northwestern China. Journal of Arid Land, 8(5): 670-680. doi: 10.1007/s40333-016-0052-5

Aeolian dune fields are among the most striking natural landform patterns (Hallet, 1990). These patterns have been considered to result from self-organization within complex systems, in contrast with traditional modeling approaches based on reductionism and universality that are incompatible with the nonlinear and dissipative nature of natural systems (Werner, 1999). Pattern

*Corresponding author: LI Jiyan (E-mail: jyli@1zb.ac.cn)
Received 2015-10-14; revised 2016-03-15; accepted 2016-04-01
(C) Xinjiang Institute of Ecology and Geography, Chinese Academy of Sciences, Science Press and Springer-Verlag Berlin Heidelberg 2016 
analysis is based on the assumption that pattern parameters are time-dependent variables that emerge through self-organization and that evolve by means of bedform-bedform interactions (Werner, 1995; Werner and Kocurek, 1997, 1999). Because of the easy access to images of the dune fields and the feasibility of direct measurements of various pattern parameters in the field or via remote images, many researchers have performed pattern analysis for aeolian dune fields on the Earth (Beveridge et al., 2006; Ewing et al., 2006; Derickson et al., 2008; Ewing and Kocurek, 2010; Wu and Guo, 2012), Mars (Ewing et al., 2010) and Titan (Ewing et al., 2015).

Dune field patterns can be classified as simple or complex (Kocurek and Ewing, 2005). The simple pattern typically consists of a single dune type, with either a homogeneous or a spatially diverse dune pattern, whereas the complex pattern consists of multiple simple dune patterns that are spatially superimposed. By using pattern analysis, it becomes possible to identify the pattern population(s) of a dune field. The type and orientation of the dune crests are determined by local wind regimes (Rubin and Hunter, 1987; Werner, 1995). A given wind regime during a certain period of dune construction results in a simple pattern, whereas complex dune patterns arise when each pattern represents a different period of dune construction under different wind regimes. By determining the formation age of each component of the overall pattern, it is possible to reconstruct the geomorphic evolution of the dune field patterns and clarify details of the construction processes and of the paleo-wind regimes in a dune field (Lancaster et al., 2002).

Models and theoretical analyses indicate that the evolution of dune field patterns derives from interactions between dunes over time (Werner, 1995; Werner and Kocurek, 1997, 1999). Therefore, the pattern parameters at a given time are a function of the date of dune field construction. Generally speaking, with the passage of time, a dune field shows a tendency towards increased inter-crest spacing and crest length, decreased defect density, more tightly clustered dune crest orientations and a reduction in the variance of the pattern parameters (Ewing et al., 2006). Moreover, because the evolution of the dune field patterns is a function of time (Werner and Kocurek, 1999; Ewing et al., 2006), the pattern parameters can be used to date the evolution of a pattern for a dune field whose age is not otherwise known, thereby augmenting current methods of age determination. Pattern analysis has therefore helped researchers to infer details of the evolution of the inaccessible dune fields on Mars (Edgett and Blumberg, 1994; Lee and Thomas, 1995) and Titan (Lancaster, 2006; Lorenz et al., 2006).

The linear dunes at the northern margin of Qarhan Salt Lake in the Qaidam Basin of northwestern China, have been studied for decades, leading to heated debates in recent years. The dunes in this area were described by Petrov (1976), who noted their markedly saline nature. After the construction of the Qinghai-Tibet Railway, Qian (1986) and Qian and Liu (1994) investigated the aeolian disasters (e.g. sandstorms and burial of the railway) that resulted from blowing sands and the elongation of these linear dunes. By examining the internal sedimentary structures of these dunes, Hesp et al. (1989) inferred the lateral migration of linear dunes, and estimated a lateral migration speed of up to $3 \mathrm{~m} / \mathrm{a}$. In recent years, with the discovery of linear dunes on Mars (Edgett and Blumberg, 1994; Lee and Thomas, 1995) and Titan (Lancaster, 2006; Lorenz et al., 2006), the formation mechanisms of extraterrestrial linear dunes was extrapolated based on their characteristics on the Earth. Rubin and Hesp (2009) proposed a self-extending model for dunes in the Qaidam Basin. These dunes formed in a unidirectional wind regime and extended downwind owing to the high cohesiveness of dune sediments that contain large amounts of total silt, clay and soluble salts. In contrast, Zhou et al. (2012) believed that the linear dunes in the Qaidam Basin had an erosional origin, based on an analysis of the constituents of the dune sediments, the internal structures and age estimates by means of optically stimulated luminescence. However, Rubin and Rubin (2013) and Yu et al. (2015) questioned the erosional origin. Zhou et al. (2013) nonetheless insisted on their standpoint in a reply to these doubts. Thus, the formation mechanism of linear dunes in the Qaidam Basin remains openly disputed.

In the present study, by providing additional morphological data of these linear dunes, we are hoping to reconsider the problem by other means. To do so, we set out to (1) identify the patterns within the linear dune field; (2) describe the statistical features and spatial variation of the pattern parameters for each pattern population; (3) discuss the evolution stages and formation mechanism 
for dunes in the study area; and (4) revise the present depositional versus erosional origin theories proposed for the studied linear dune field.

\section{Study area and methods}

Qarhan Salt Lake is located in the central-southern part of Qaidam Basin, and is currently mostly dry; it therefore represents an extensive playa area of about $5,856 \mathrm{~km}^{2}$, with a few shallow brine lakes (Fig. 1a). The brine lakes in Qarhan Salt Lake playa are co-fed by ground water and seasonal rivers that originate south of the basin in the Kunlun Mountains. The climate is arid to hyper-arid, with an average annual precipitation of $24.7 \mathrm{~mm}$ and potential evaporation of more than 3,500 $\mathrm{mm}$. Owing to high evaporation and low recharge, the brine lakes have been gradually shrinking and the dry playa has been continuously expanding in the area. Because of the hyper-arid conditions, there is little vegetation on the linear dunes. The linear dune field in this study lies at the northern margin of Qarhan Salt Lake. It is long (about $24.5 \mathrm{~km}$ ) and narrow (about $3.5 \mathrm{~km}$ ), forming a strip that runs from west-northwest to east-southeast (Fig. 1b). The dune field lies at an elevation of 2,700-2,735 m asl, and is bounded by the piedmont fluvial-diluvial plains in the north. At the north-northwestern end margin, there distributes a yardang field and extensive pavements of gravels (Li et al., 2016). These landforms may be the potential sand source of the studied dune field. The study area is characterized by a widely unimodal wind regime, and the dominant wind blows from the west to the northwest (Fig. 1c).

To obtain the data required to calculate the pattern parameters, we acquired Landsat 8 Operational Land Imager satellite images of the area. By sharpening the true colors of wave bands 4, 3 and 2 using panchromatic wave band 8 with version 5.0 of ENVI software (http://www.exelisvis.com), we obtained an image with a spatial resolution of $15 \mathrm{~m}$. We then manually traced the linear dune crests (Fig. 1d) and measured three pattern parameters (the inter-crest spacing, crest length and crest orientation) using version 10.0 of the ArcGIS software (http://www.esri.com). We followed the definition of pattern parameters and the measurements method proposed by Ewing et al. (2006). Because of the limitation of the area of the study region, we measured a total of only 128 dune crest lengths and orientation, and 580 inter-crest spacing. We used the inverse distance weighted interpolation method provided by ArcGIS to obtain contour maps to demonstrate the spatial variation of the pattern parameters. Defect density is the number of defect pairs (N) per unit dune crest length (L): $\rho=\mathrm{N} / \mathrm{L}$ (Werner and Kocurek, 1999). Here, a defect pair was defined as Werner and Kocurek (1997).

Dune height was measured in the upwind, central and downwind areas of the dune field using a TruPulse 200 Laser Rangefinder (http://www.lasertech.com). At each position, we measured two transects at a parallel distance of $1 \mathrm{~km}$ and obtained a total of 31 dune heights. We used these data to analyze the relationship between dune height and the corresponding inter-crest spacing. To obtain data on the local wind regime, we mounted an automatic wind observation tower on a mast $2 \mathrm{~m}$ above the ground surface in the flat area between dunes, upwind of one linear dune, and at one site towards the center of the dune field to automatically record the wind speed and direction at 15-min intervals. We used wind data from July 2009 to August 2010 to calculate the drift potential and related parameters for the study area according to the methods proposed by Fryberger and Dean (1979). In this calculation, a threshold wind velocity of $6 \mathrm{~m} / \mathrm{s}$ was applied because it represents a wind strong enough to entrain sand particles (Wang et al., 2005).

\section{Results}

\subsection{Inter-crest spacing and crest length}

Beveridge et al. (2006) and Ewing et al. (2006) indicated that among the dune pattern parameters, inter-crest spacing is the one that best differentiates among pattern populations in a dune field in a cumulative probability plot. The inter-crest spacing mainly ranged from 100 to $700 \mathrm{~m}$ (accounting for $84.5 \%$ of the values), and spacing $<100$ and $>700 \mathrm{~m}$ accounted for $4.5 \%$ and $11.0 \%$ of the total, respectively (Fig. 2a). Values of $>2,000 \mathrm{~m}$ accounted for $0.5 \%$ of the total. The presence of 


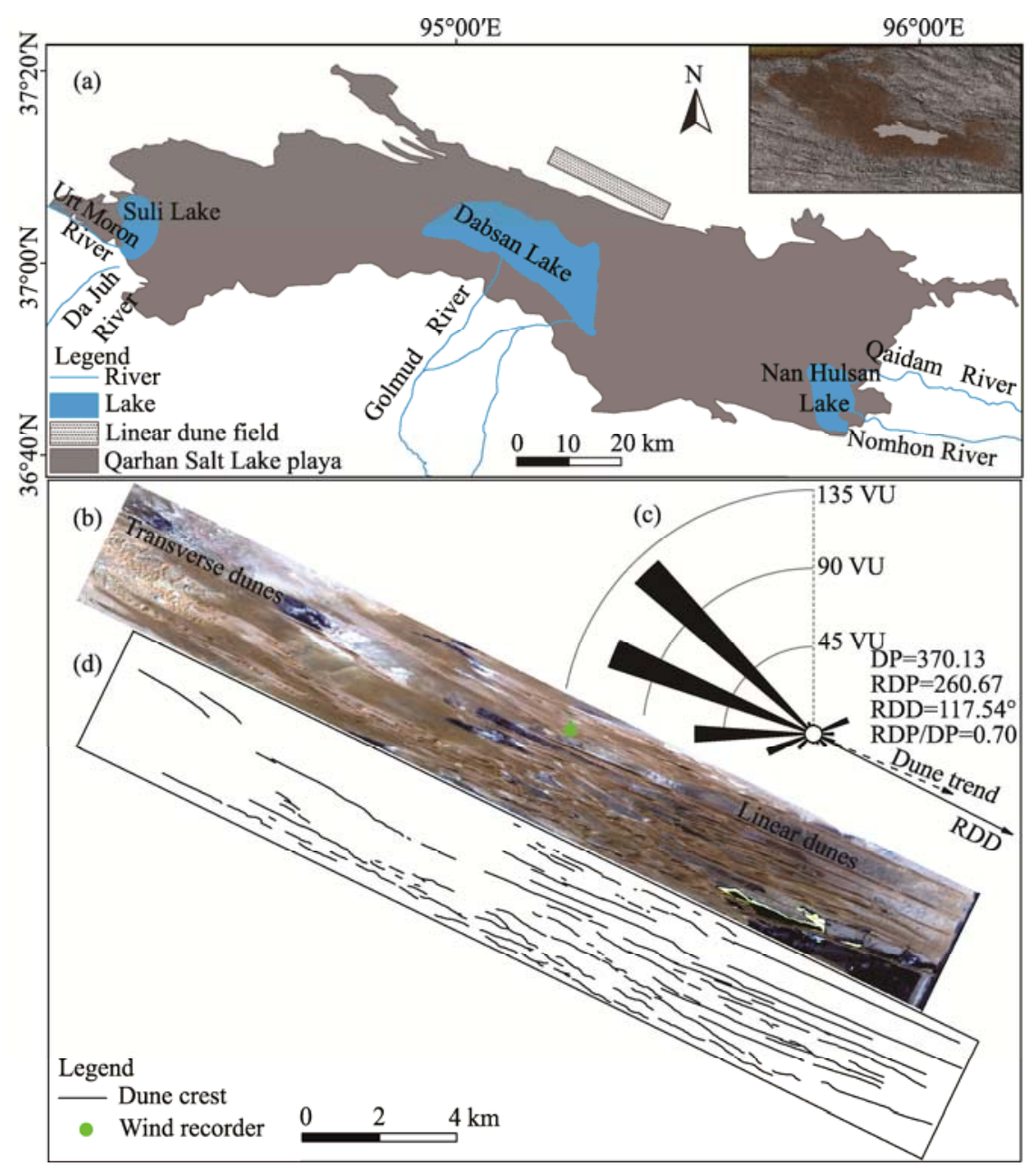

Fig. 1 The location of Qarhan Salt Lake playa and the linear dune field (rectangular area in the north of the playa; a); Landsat 8 Operational Land Imager satellite images of linear dunes (b); wind regime in the study area (c); and manually traced dune crests (d). DP, drift potential; RDP, resultant drift potential; RDD, resultant drift direction; VU, vector unit.

two inflection points in the cumulative probability plot for the inter-crest spacing (Fig. 3a) demonstrated that the linear dunes can be classified into three populations. The inter-crest spacing of dunes in the first population was less than $130 \mathrm{~m}$, and these dunes featured residual linear ridges. They were individual, free-standing relics of larger linear dunes (Fig. 4a) or were connected with other linear ridges by a sand sheet without an obvious dune crest (Fig. 4b). The second population comprised linear dunes with an inter-crest spacing between 130 and $300 \mathrm{~m}$. It represented linear dunes whose sand supply roughly equaled the loss to erosion, and these dunes were much larger than those in the first population, with a much wider inter-crest spacing and a more regular distribution (Fig. 4c). The third population comprised dunes with an inter-crest spacing larger than $300 \mathrm{~m}$. These linear dunes may be subject to sustaining erosion at the upwind end or other positions, but they continue to grow vertically and elongate in the downwind direction (Fig. 4d).

Compared with the inter-crest spacing, the dune crest length is a less powerful parameter for recognizing distinct pattern populations in a dune field (Derickson et al., 2008; Dong et al., 2011; $\mathrm{Wu}$ and Guo, 2012). The measured 128 dune crest lengths showed a multi-modal distribution (Fig. $2 b)$. The proportion of dune crest length $>900 \mathrm{~m}$ was largest (46.1\% of the total), that of 200-900 $\mathrm{m}$ was in the second place $(36.7 \%$ of the total), while that of $<200 \mathrm{~m}$ was the lowest (accounting for the rest $17.2 \%$ ). Despite the data limitation, the cumulative probability plot for crest length also revealed three discrete sections separated by inflection points at 200 and $900 \mathrm{~m}$ (Fig. 3b). 

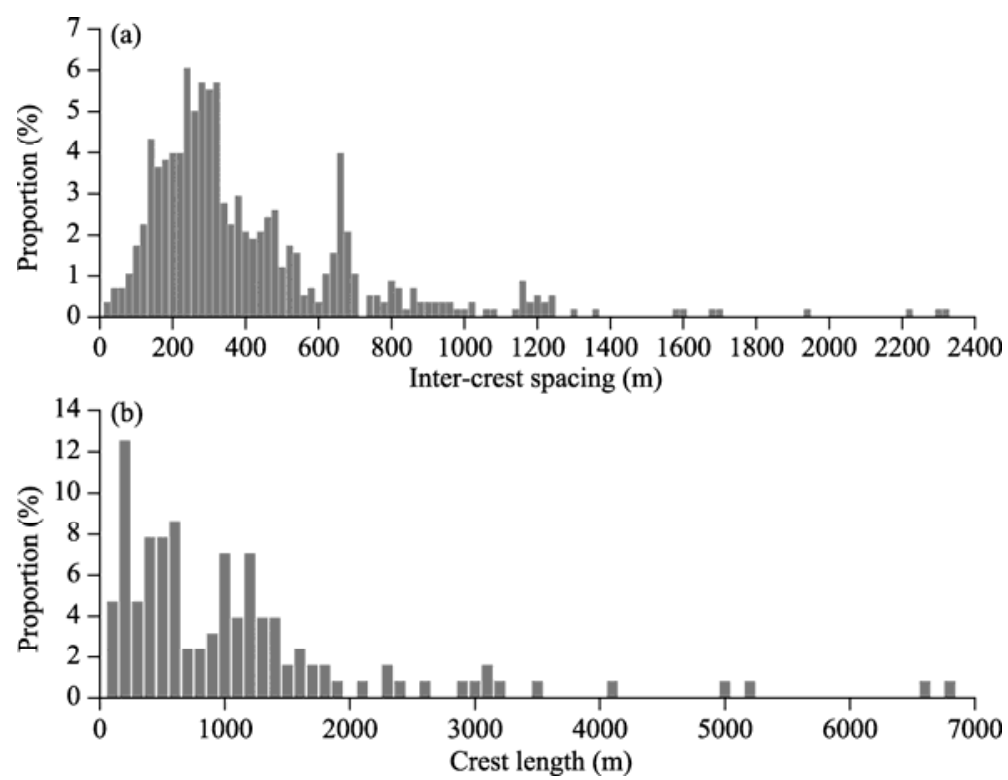

Fig. 2 Probability distributions for the inter-crest spacing (a) and crest length (b) of linear dunes
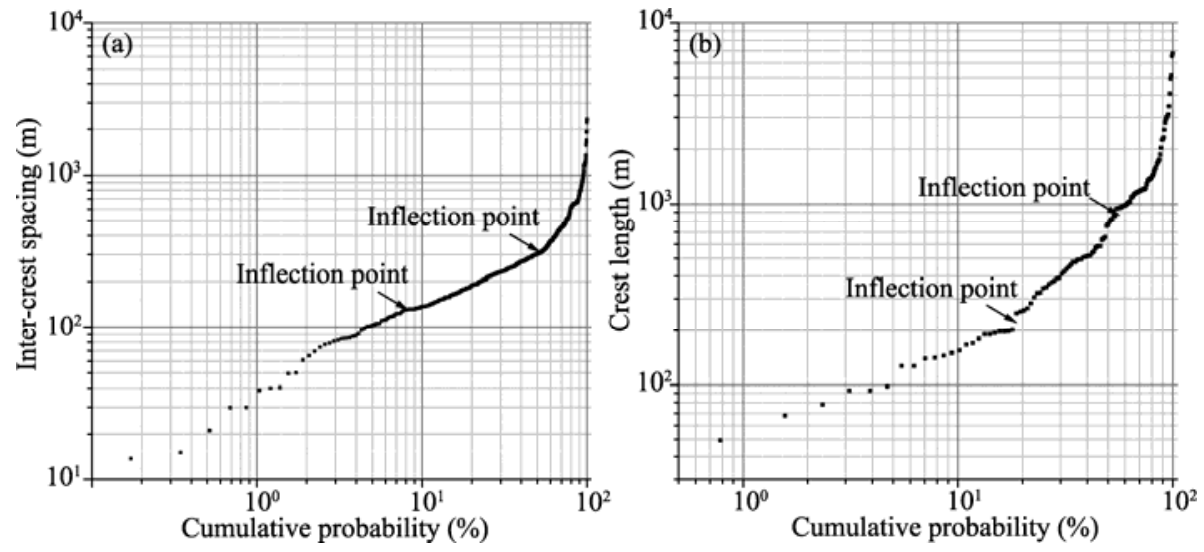

Fig. 3 Cumulative probability plots for the inter-crest spacing (a) and crest length (b) of linear dunes
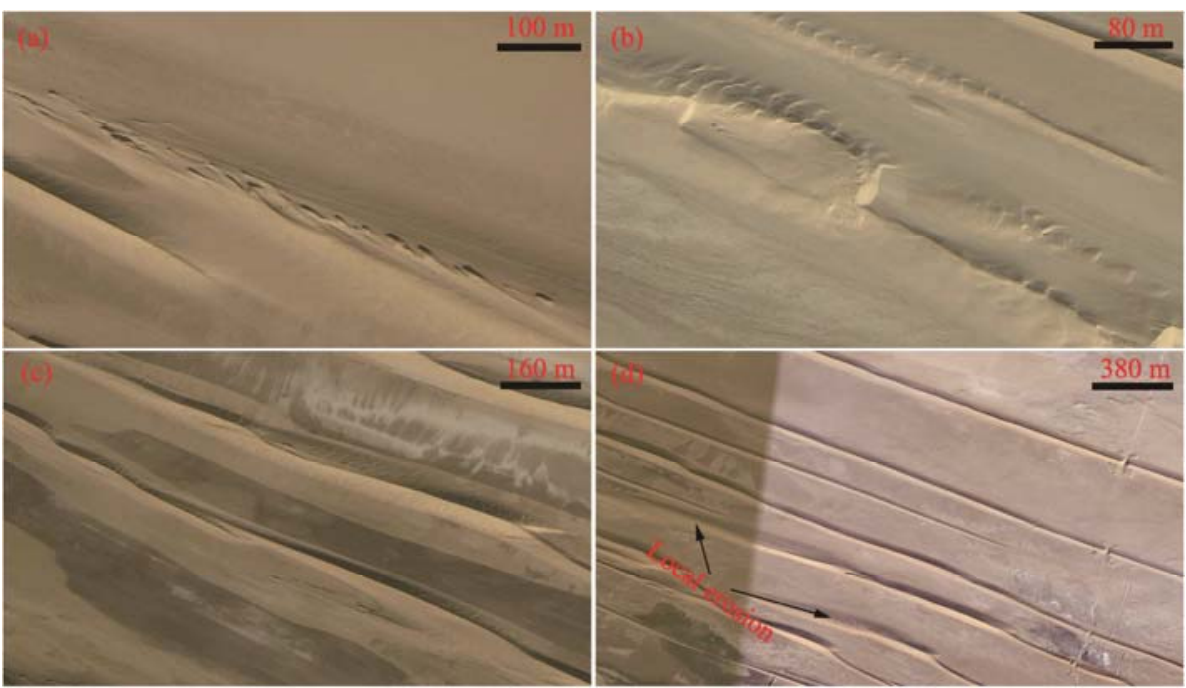

Fig. 4 Linear dunes in different evolution stages 
Except at the upwind end area, the spatial variation of inter-crest spacing was characterized by a gradual increasing trend from the up-middle part towards the downwind end of the dune field (Fig. 5a). At the west-northwest margin of the dune field, the linear dunes developed from the lee end of yardangs, which can be regarded as evidence that validates the formation mechanism proposed by Rubin and Hesp (2009). The inter-crest spacing of linear dunes in this area appears to be mainly affected by topographic obstacles (i.e. yardangs), which leads to a much larger and more irregular spacing. The dune field terminates at the Qinghai-Tibet Railway at the downwind end. For controlling aeolian hazards along the railway, the dunes in this area have been artificially stabilized (Rubin and Rubin, 2013; Yu et al., 2015).

As a whole, except at the upwind end area, the spatial variation of crest length also showed an increasing tendency from the up-middle part towards the downwind end (Fig. 5b). The crest length of linear dunes reached its maximum at the downwind end of the dune field, where sand-stabilization engineering had been performed. Such a spatial variation pattern for crest length corroborates the evolution theory proposed by Werner and Kocurek (1999) and Ewing et al. (2006), who believed that linear dunes evolve through a process of dune crest elongation.

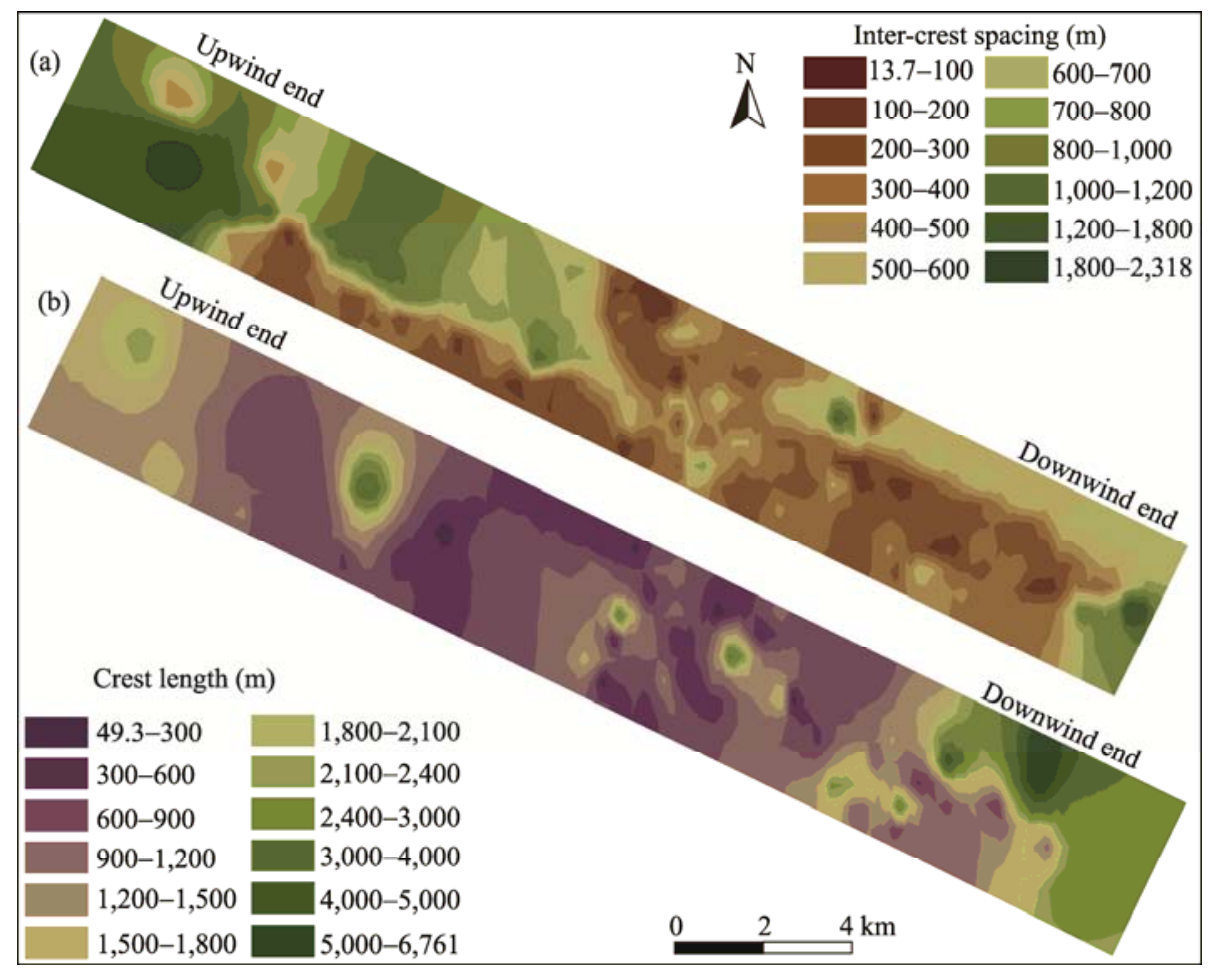

Fig. 5 Interpolated contour maps for the spatial variation in the inter-crest spacing (a) and crest length (b) of linear dunes

\subsection{Dune orientation and defect density}

Dune orientation also comes as an important pattern parameter, and is mainly affected by the local wind regime. Of the three pattern parameters, dune orientation took the smallest coefficient of variation, suggesting a high degree of spatial homogeneity. A total of 128 dune orientation values was measured in this study. These values ranged between $100.8^{\circ}$ and $135.3^{\circ}$, with a mean of $117.8^{\circ}$, which was in accordance with the resultant drift direction (RDD) in the study area (Fig. 1c). The strikes of the dune crests most often ranged between $110^{\circ}$ and $125^{\circ}(85.2 \%$ of the total), while strikes $<110^{\circ}$ and $>125^{\circ}$ accounted for only $5.5 \%$ and $9.4 \%$, respectively (Fig. 6a).

The dune crest orientation tended to decrease in the downwind direction (Fig. 6b), which was opposite to the trend for crest length. The orientation of linear dunes at the upwind end could exceed $130^{\circ}$ and gradually decreased to less than $110^{\circ}$ at the downwind end. At the upwind end of 
the dune field, the strikes of linear dunes may have been controlled by the orientation of the yardangs. When the dunes extended sufficiently far into the flat dry playa where they no longer experienced the impact of yardangs, the crest orientation would be mainly dominated by the regnant wind-flow patterns. Thus, the orientation of the dune crests was evolved so that it became parallel to the RDD (Fig. 1c).

Defect density is another crucial parameter of pattern populations at the dune field scale. Based on the method proposed by Werner and Kocurek $(1997,1999)$, the defect density of the dune field was calculated as $9.3 \times 10^{-4}$, which represents a density of nearly one pair of defects per kilometer. This defect density was slightly smaller than the value for the population A linear dunes that formed $5 \mathrm{ka}$ BP in the Agneitir Sand Sea of Mauritania (Table 1), and much larger than the values for the population B and C linear dunes in the same location (Ewing et al., 2006). Table 1 showed that our calculated defect density was also much larger than the values for the Namib Sand Sea (Ewing et al., 2006), Gran Desierto Dune Field of Mexico (Beveridge et al., 2006), Algodones Dune Field of southern California (Derickson et al., 2008) and the Kumtagh Desert of northern China (Wu and Guo, 2012). Such a large defect density indicates that the linear dunes are young and that most of the dunes are still in their vertical accretion and longitudinal elongation stage.

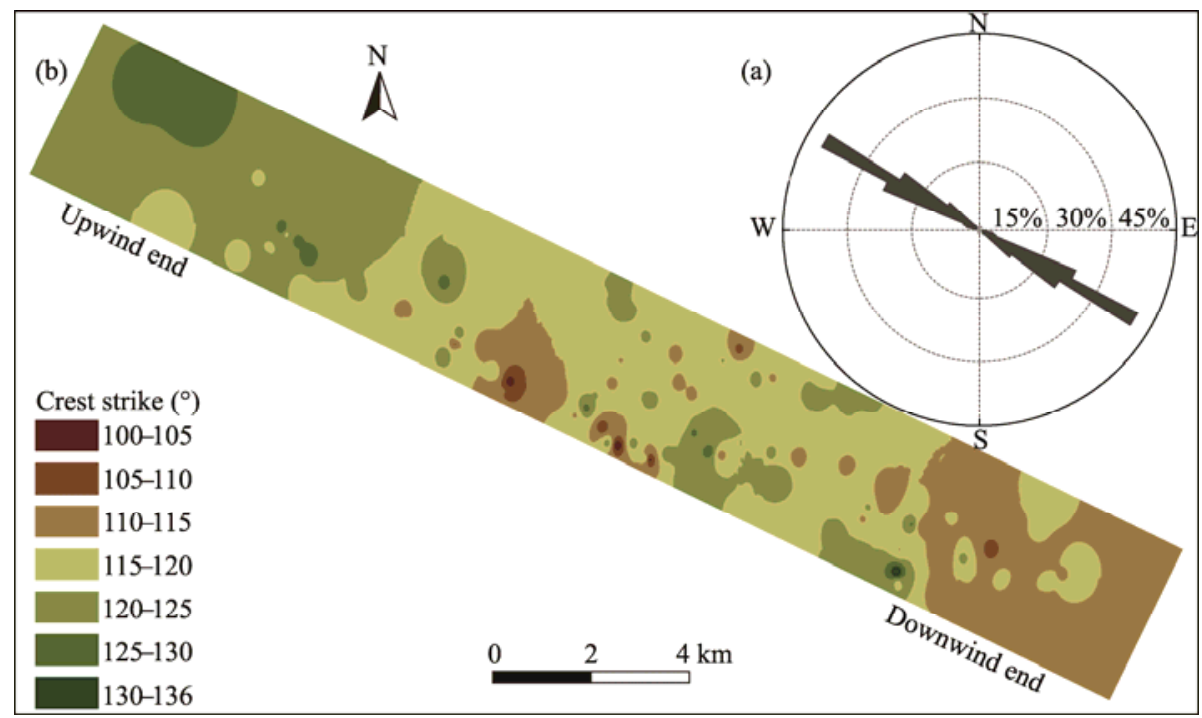

Fig. 6 Probability distribution (a) and interpolated contour map (b) of the spatial variation in dune crest orientation

Table 1 Comparison of the pattern parameters of linear dune fields around the world

\begin{tabular}{|c|c|c|c|c|c|c|c|c|}
\hline \multirow{2}{*}{ Region } & \multicolumn{3}{|c|}{$\begin{array}{l}\text { Inter-crest spacing } \\
(\mathrm{m})\end{array}$} & \multicolumn{3}{|c|}{ Crest length (m) } & \multirow{2}{*}{$\begin{array}{l}\text { Defect } \\
\text { density }\end{array}$} & \multirow[t]{2}{*}{ Reference } \\
\hline & Mean & $\mathrm{SD}$ & $\mathrm{CV}$ & Mean & SD & $\mathrm{CV}$ & & \\
\hline Agneitir Sand Sea & & & & & & & & Ewing et al. (2006) \\
\hline Population A & 172 & 53 & 0.3 & 620 & 258 & 0.41 & $16.00 \times 10^{-4}$ & \\
\hline Population B & 682 & 363 & 0.5 & 11,158 & 10,566 & 0.79 & $1.10 \times 10^{-4}$ & \\
\hline Population $\mathrm{C}$ & 4,105 & 829 & 0.2 & - & - & - & $0.26 \times 10^{-4}$ & \\
\hline Namib Sand Sea & 2,253 & 455 & 0.2 & - & - & - & $0.15 \times 10^{-4}$ & \\
\hline $\begin{array}{l}\text { Gran Desierto Dune } \\
\text { Field }\end{array}$ & 2,308 & 825 & 0.4 & 4,378 & 2,330 & 0.53 & $2.28 \times 10^{-4}$ & $\begin{array}{l}\text { Beveridge et al. } \\
(2006)\end{array}$ \\
\hline Algodones Dune Field & 250 & 86 & 0.3 & 11,529 & 12,425 & 1.08 & $1.50 \times 10^{-4}$ & $\begin{array}{l}\text { Derickson et al. } \\
(2008)\end{array}$ \\
\hline Kumtagh Desert & 1,132 & 804 & 0.7 & 4,271 & 3,823 & 0.90 & $1.40 \times 10^{-4}$ & Wu and Guo (2012) \\
\hline Qarhan Salt Lake & 304 & 311 & 0.8 & 1,073 & 1,173 & 1.09 & $9.30 \times 10^{-4}$ & This study \\
\hline
\end{tabular}

Note: "-" means data not available. SD, standard deviation; CV, coefficient of variation. 


\subsection{Height-spacing relationship}

The bedforms that are maintained by the wind, including aeolian sand dunes and wind ripples, are characterized by a regular relationship between dune height and inter-crest spacing. Figure 7 shows the height-spacing relationship for the linear dunes on the Earth and Titan. The results indicated that the linear dunes of Qarhan Salt Lake shared a similar geometry (inter-crest spacing, above inter-dune height) with their counterparts in the southwestern Kalahari Desert, Simpson-Strzelecki Desert and Great Sandy Desert. The dunes in Qarhan Salt Lake were much shorter and more closely spaced than the linear dunes in the Namib Sand Sea and on Titan. Being different from the simple and compound vegetated linear dunes in the southwestern Kalahari Desert, Simpson-Strzelecki Desert and Great Sandy Desert and the complex linear dunes in the Namib Sand Sea, the dunes in Qarhan Salt Lake were all simple linear dunes without any vegetation cover. Although the data in Fig. 7 showed a high degree of scattering, the relationships could all be described by linear equations on an lg-lg graph. The similarity of the geometry for the linear dunes in Qarhan Salt Lake area with that of the vegetated linear dunes may indicate similar formation mechanisms.

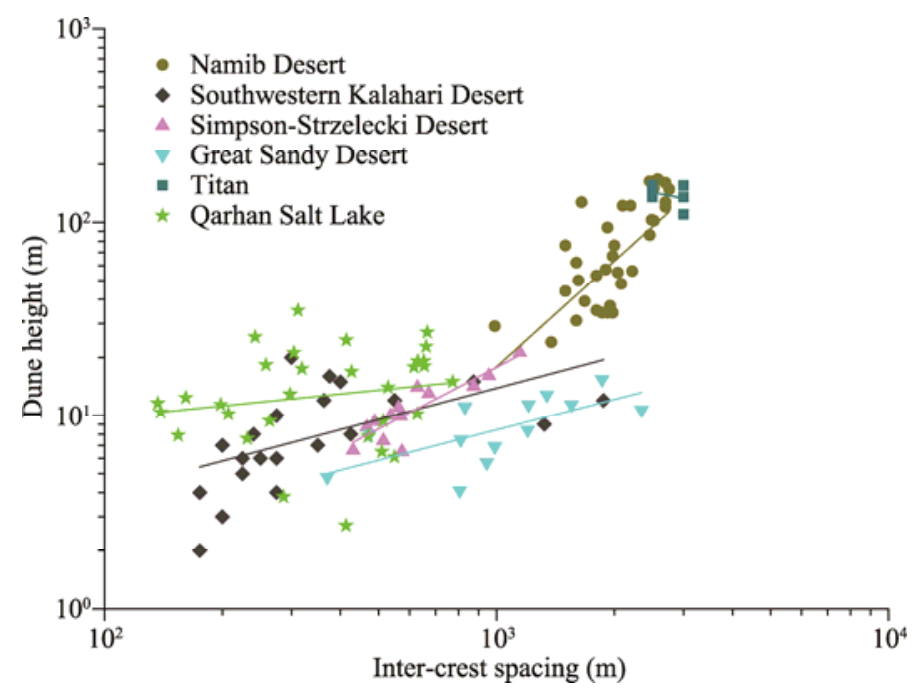

Fig. 7 The relationships between dune height and inter-crest spacing for linear dunes on the Earth and Titan. Data were from Lancaster $(1995,2006)$ and Lorenz et al. (2006).

\section{Discussion}

\subsection{Evolution stages of linear dunes of Qarhan Salt Lake}

Linear dunes can be classified into three main types: simple, compound and complex (McKee, 1979). Compound linear dunes represent smaller linear dunes superimposed on the major ridges, and complex linear dunes have different sub-types, such as star or crescentic dunes superimposed on the major ridges. According to this classification, the linear dunes in Qarhan Salt Lake are all simple dunes. Nonetheless, they can be divided into three groups based on the cumulative probability plots for inter-crest spacing and dune crest length.

According to the three groups divided by the pattern parameters, we can tentatively classify the linear dunes in the study area into three developmental stages. Where the sand supply is limited, the linear dunes cannot consistently grow in height or elongate downwind. When the dunes attain a certain height, vertical accretion is displaced by aeolian erosion at the upwind end and other positions, thereby sustaining elongation in the downwind direction. When the input of sand to a linear dune cannot balance the loss of sand to erosion, the dune begins shrinking. Thus, taller and longer linear dunes will be eroded into one or more smaller and shorter linear dune relics, corresponding to the first group of linear dunes in the dune field. Moreover, when the input of 
sand balances the loss to erosion, the size of the linear dune will remain roughly constant. These represent the second group of linear dunes. Finally, some of linear dunes receive much more sand than they loss to erosion, leading to vertical accretion and longitudinal elongation. These dunes are still in their developmental stage, and represent the third group of linear dunes. This group is predominantly found at the downwind end of the dune field. The first two groups of linear dunes are or will soon be in their degradation stage, whereas members of the third group are still in their vertical accretion and longitudinal elongation stage. Thus, it can be envisaged that if the sand supply conditions remain stable, the linear dune field in the study area will disappear as sand stabilization engineering for the Qinghai-Tibetan Railway prevents further downwind elongation of the dunes, which are, all the while, under continuous aeolian erosion.

\subsection{Formation mechanisms of linear dunes of Qarhan Salt Lake}

The debate over the formation mechanism of linear dunes mainly focuses on their erosional or depositional origins. Previous researches suggest that linear dunes primarily develop under two environmental settings: where bidirectional winds blow over loose and soft sediments, and where unidirectional winds blow across cohesive sediments (Rubin and Hesp, 2009). Given the flat dry playa surface and scarce vegetation cover on dunes, the formation and development of linear dunes in the study area are likely to be mainly affected by two factors: wind regime and sediment characteristics.

Wind regime is the key factor in the development and evolution of dunes. It not only provides the motive power that is responsible for the movement of sand by creep and saltation, but also controls the direction in which the dunes strike (Qian et al., 2012). Wind regimes associated with active linear dunes range from widely unimodal through complex. Based on the categories of Fryberger and Dean (1979), our study area is characterized by an intermediate wind energy, with a widely unimodal wind regime (Fig. 1c). Such a wind regime would promote the formation of transverse dunes, and indeed, there is an area of transverse dunes at the upwind edge of our study area (Fig. 1b). In our study area, sand-driving winds blow predominantly from the west, west-northwest and northwest, and the drift potential from these directions represent $81.7 \%$ of the annual total. This kind of wind regime would be expected to produce the linear dunes found in most of our study area.

The similarity of the geometry between the linear dunes in Qarhan Salt Lake and those in the southwestern Kalahari Desert, Simpson-Strzelecki Desert and Great Sandy Desert suggests similar formation mechanisms for them. A major difference between these dune fields is that the linear dunes in the present study have no vegetation cover. Vegetation plays a decisive role in stabilizing vegetated linear dunes during and after their formation (Tsoar and Møller, 1986; Wiggs et al., 1995; Herrmann et al., 2008). Therefore, some other factors must replace the role of vegetation in stabilizing the linear dunes of Qarhan Salt Lake. One possibility is the nature of the sediments. Rubin and Hesp (2009) believed that a high content of silt, clay and soluble salts increases the cohesiveness of linear dune sediments, and based on this perspective they proposed a self-extending model for these dunes. However, on the basis of the erosional exposed joints and internal sedimentary structures, Zhou et al. (2012) proposed an erosional origin for the linear dunes in the study area. Therefore, it seems that both hypotheses are correct for different parts of the dune field: Zhou's erosional hypothesis (Zhou et al., 2012) is more reasonable for at least some dunes in the upwind portion, whereas depositional hypothesis of Rubin and Hesp (2009) holds correctness for at least some dunes in the downwind portions.

In addition, both processes are likely to operate in some parts of the dune field. For example, in the central part of the dune field, deposition is largely balanced by erosion, leading to net stability of the dunes, at least in the short term. That is to say, depositional and erosional processes coexist at the same time during the linear dune development in the study area. However, these hypotheses should be verified by additional evidence, such as longer-term wind regime observations and more detailed examination of the internal structures of the dunes and constituents of dune sediments. 


\section{Conclusions}

Except for the linear dunes at the west-northwest margin of the dune field, whose formation may be largely attributable to the effects of upwind yardangs, the pattern parameters of inter-crest spacing, crest length and dune orientation all showed relatively regular spatial variation from the up-middle part towards the downwind end of the studied dune field. Based on our analysis of the pattern parameters for the linear dunes in Qarhan Salt Lake area, we divided the dunes into three types by evolution stages: (1) erosion relics that are in a recession stage; (2) dunes whose sand supply balances their loss to erosion and that are stable or will soon enter a recession stage; and (3) dunes that are still undergoing vertical accretion and longitudinal elongation, and which are not yet mature.

Accordingly, depositional and erosional processes coexist at different parts of the studied dune field or different evolution stages of linear dunes. However, for supporting this hypothesis, it will be necessary to obtain more data on the internal structures of the dunes, on the constituents of the dune sediments and on long-term observations of the wind regime.

\section{Acknowledgements}

This study was funded by the National Basic Research Program of China (2013CB956000) and the National Natural Science Foundation of China (41171010, 41371102, 41301003). This paper benefited significantly from four anonymous reviewers.

\section{References}

Beveridge C, Kocurek G, Ewing R C, et al. 2006. Development of spatially diverse and complex dune-field patterns: Gran Desierto Dune Field, Sonora, Mexico. Sedimentology, 53(6): 1391-1409.

Derickson D, Kocurek G, Ewing R C, et al. 2008. Origin of a complex and spatially diverse dune-field pattern, Algodones, southeastern California. Geomorphology, 99(1-4): 186-204.

Dong Z B, Su Z Z, Qian G Q, et al. 2011. Aeolian Geomorphology of the Kumtagh Desert. Beijing: Science Press, 354-369. (in Chinese)

Edgett K S, Blumberg D G. 1994. Star and linear dunes on Mars. Icarus, 112(2): 448-464.

Ewing R C, Kocurek G, Lake L W. 2006. Pattern analysis of dune-field parameters. Earth Surface Processes and Landforms, 31(9): 1176-1191.

Ewing R C, Kocurek G A. 2010. Aeolian dune interactions and dune-field pattern formation: White Sands Dune Field, New Mexico. Sedimentology, 57(5): 1199-1219.

Ewing R C, Peyret A P B, Kocurek G, et al. 2010. Dune field pattern formation and recent transporting winds in the Olympia Undae Dune Field, north polar region of Mars. Journal of Geophysical Research, 115(E8): E08005, doi: 10.1029/2009JE003526.

Ewing R C, Hayes A G, Lucas A. 2015. Sand dune patterns on Titan controlled by long-term climate cycles. Nature Geoscience, 8(1): 15-19.

Fryberger S G, Dean G. 1979. Dune forms and wind regime. In: McKee E D. A Study of Global Sand Seas. United States Geological Survey Professional Paper 1052. Hawaii: University Press of the Pacific, 137-169.

Hallet B. 1990. Spatial self-organization in geomorphology: From periodic bedforms and patterned ground to scale-invariant topography. Earth-Science Reviews, 29(1-4): 57-75.

Herrmann H J, Durán O, Parteli E J R, et al. 2008. Vegetation and induration as sand dunes stabilizators. Journal of Coastal Research, 24(6): 1357-1368.

Hesp P A, Hyde R, Hesp V, et al. 1989. Longitudinal dunes can move sideways. Earth Surface Processes and Landforms, 14(5): 447-451.

Kocurek G, Ewing R C. 2005. Aeolian dune field self-organization-implications for the formation of simple versus complex dune-field patterns. Geomorphology, 72(1-4): 94-105.

Lancaster N. 1995. Geomorphology of Desert Dunes. London: Routledge, 48-56.

Lancaster N, Kocurek G, Singhvi A, et al. 2002. Late Pleistocene and Holocene dune activity and wind regimes in the western Sahara Desert of Mauritania. Geology, 30(11): 991-994.

Lancaster N. 2006. Linear dunes on Titan. Science, 312(5774): 702-703. 
Lee P, Thomas P C. 1995. Longitudinal dunes on Mars: Relation to current wind regimes. Journal of Geophysical Research, 100(E3): 5381-5395.

Li J Y, Dong Z B, Qian G Q, et al. 2016. Yardangs in the Qaidam Basin, northwestern China: Distribution and morphology. Aeolian Research, 20: 89-99.

Lorenz R D, Wall S, Radebaugh J, et al. 2006. The sand seas of Titan: Cassini RADAR observations of longitudinal dunes. Science, 312(5774): 724-727.

McKee E D. 1979. Introduction to a study of global sand seas. In: McKee E D. A Study of Global Sand Seas. United States Geological Survey Professional Paper 1052. Hawaii: University Press of the Pacific, 1-19.

Petrov M P. 1976. Deserts of the World. New York: John Wiley \& Sons.

Qian G Q, Dong Z B, Zhang Z C, et al. 2012. Granule ripples in the Kumtagh Desert, China: Morphology, grain size and influencing factors. Sedimentology, 59(6): 1888-1901.

Qian Z Y. 1986. Investigations on the sand harm to Qinghai-Xizang railway in Yanqiao area and sand control plan. Journal of Desert Research, 6(2): 27-30. (in Chinese)

Qian Z Y, Liu S Q. 1994. Research on aeolian sand characteristics and depositional structures of linear dunes. Journal of Desert Research, 14(3): 25-30. (in Chinese)

Rubin D M, Hunter R E. 1987. Bedform alignment in directionally varying flows. Science, 237(4812): 276-278.

Rubin D M, Hesp P A. 2009. Multiple origins of linear dunes on Earth and Titan. Nature Geoscience, 2(9): $653-658$.

Rubin D M, Rubin A M. 2013. Origin and lateral migration of linear dunes in the Qaidam Basin of NW China revealed by dune sediments, internal structures, and optically stimulated luminescence ages, with implications for linear dunes on Titan: discussion. Geological Society of America Bulletin, 125(11-12): 1943-1946.

Tsoar H, Møller J T. 1986. The role of vegetation in the formation of linear sand dunes. In: Nickling W G. Aeolian Geomorphology. Boston: Allen \& Unwin, 75-95.

Wang X M, Dong Z B, Yan P, et al. 2005. Wind energy environments and dunefield activity in the Chinese deserts. Geomorphology, 65(1-2): 33-48.

Werner B T. 1995. Eolian dunes: computer simulations and attractor interpretation. Geology, 23(12): 1107-1110.

Werner B T, Kocurek G. 1997. Bed-form dynamics: Does the tail wag the dog?. Geology, 25(9): 771-774.

Werner B T. 1999. Complexity in natural landform patterns. Science, 284(5411): 102-104.

Werner B T, Kocurek G. 1999. Bedform spacing from defect dynamics. Geology, 27(8): 727-730.

Wiggs G F S, Thomas D S G, Bullard J E, et al. 1995. Dune mobility and vegetation cover in the Southwest Kalahari desert. Earth Surface Processes and Landforms, 20(6): 515-529.

Wu J F, Guo F. 2012. Geomorphological patterns in a linear dune field and ages of the linear dunes in the northern Kumtagh Desert, northwest China. Environmental Earth Sciences, 66(8): 2449-2457.

Yu L P, Dong Z B, Lai Z P, et al. 2015. Origin and lateral migration of linear dunes in the Qaidam Basin of NW China revealed by dune sediments, internal structures, and optically stimulated luminescence ages, with implications for linear dunes on Titan: comment and discussion. Geological Society of America Bulletin, 127(1-2): 316-320.

Zhou J, Zhu Y, Yuan C. 2012. Origin and lateral migration of linear dunes in the Qaidam Basin of NW China revealed by dune sediments, internal structures, and optically stimulated luminescence ages, with implications for linear dunes on Titan. Geological Society of America Bulletin, 124(7-8): 1147-1154.

Zhou J, Zhu Y, Yuan C. 2013. Origin and lateral migration of linear dunes in the Qaidam Basin of NW China revealed by dune sediments, internal structures, and optically stimulated luminescence ages, with implications for linear dunes on Titan: reply. Geological Society of America Bulletin, 125(11-12): 1947-1949. 